\title{
Friction Welding of magnesium alloys
}

\author{
Zhongbao Shen ${ }^{1}$, Ranfeng. Qiu², Qingzhe Li, Longlong Hou, Lihu Cui \\ Materials Science and Engineering, Henan University of Science and Technology, Luoyang, \\ 471003, China
}

1534957297@qq.com, 2quiurf1221@163.com

Keyword: Friction welding, Magnesium alloys

Abstract: Magnesium alloys were welded by friction welding. The mechanical properties of the joint were investigated; the effects of welding parameters on flanging amount, wear amount and tensile shear load of the joints were discussed. The results show that the joint strength increases with the increase of friction force and decreases with the increase of upset force. As a result, we could obtain high quality weld joint when friction pressure is $2 \mathrm{kN}$, and upset pressure is $2 \mathrm{kN}$.

\section{Introduction}

One of the biggest challenges in the automotive and aerospace industry is developing a lighter material with a higher strength-to-weight ratio that would reduce fuel consumption and green house gases [1, 2]. Accordingly, light metals and alloys has received widespread attention, such as magnesium and its alloys, due to their intrinsic characteristics, such as low density, good mechanical property and joining characteristic [3]. In the past two decades, numerous studies have been conducted to improve the mechanical properties of magnesium and its alloys. Nguyen and Gupta [4] investigated improving mechanical properties by adding nano-alumina particulates and calcium $(\mathrm{Ca})$ in magnesium-A12O3-Ca.

Magnesium alloys are attractive because of their electromagnetic interference shielding properties and recyclability [5]. Magnesium alloys can be joined by a wide variety of process, but they all have a lot of disadvantages by using conventional joining processes. The disadvantages include a large heat affect zone (HAZ), porosity, evaporative loss of the alloying elements and high residual stresses [6].

Friction welding is a solid-state technique patented by welding institute (TWI) in 1949 which consisting of rotating one part against a stationary part while applying an axial load, eliminates the necessity for a protective environment when welding, since the material does not reach fusion temperatures.

In this paper, friction welding of magnesium was implemented under a variety of welding parameters. For analyzing the mechanical properties of joints, the tensile shear testing of joint was carried out, the effects of welding parameters on the flanging amount, wear amount and tensile shear strength were analyzed.

\section{Experiment}

The materials used in this study were AZ31B magnesium rods with a $14 \mathrm{~mm}$ diameter. The length is $145 \mathrm{~mm}$ for the fixed end and $125 \mathrm{~mm}$ for the rotate end. The oxidation film and oil soil on the surface of workpiece were removed before welding. Their chemical compositions and thermophysical property are listed in table 1 and table 2, respectively. The schematic of friction welding process is shown in Fig. 1. $\mathrm{P}_{1}$ is a kind of stress which makes the two materials meet. $\mathrm{P}_{2}$ is the upset force under welding process. The left end and right end is rotating end and fixed end, respectively.

Table 1. Chemical composition of materials (Mass \%)

\begin{tabular}{ccccccc}
\hline $\mathrm{Al}$ & $\mathrm{Zn}$ & $\mathrm{Mn}$ & $\mathrm{Fe}$ & $\mathrm{Si}$ & $\mathrm{Cu}$ & $\mathrm{Mg}$ \\
\hline 2.94 & 0.87 & 0.57 & 0.0027 & 0.0112 & 0.0008 & $\mathrm{Bal}$
\end{tabular}


Table 2. Thermo-physical property

\begin{tabular}{clllll}
\hline $\begin{array}{c}\text { Tensile } \\
\text { strength(MPa) }\end{array}$ & $\begin{array}{l}\text { Yield } \\
\text { strength(MPa) }\end{array}$ & Density $\left(\mathrm{g} / \mathrm{cm}^{3}\right)$ & $\begin{array}{l}\text { Melting } \\
\text { point }\left({ }^{\circ} \mathrm{C}\right)\end{array}$ & $\begin{array}{l}\text { Boiling } \\
\text { point }\left({ }^{\circ} \mathrm{C}\right)\end{array}$ & $\begin{array}{l}\text { Heat } \\
\text { conductivity }(\mathrm{W} / \mathrm{m} \\
\times \mathrm{k})\end{array}$ \\
\hline 290 & 150 & 1.738 & 650 & 1107 & 155.5 \\
\hline
\end{tabular}

The friction force, upset force and friction time are the main process parameters in determining the appearance and mechanical properties of friction welded joint. The friction welding parameters, which varied for the present work, are listed in table 3. Friction pressure and upset pressure was varied at the fixed other welding parameters. Friction time is $2.5 \mathrm{~s}$ which hold constant. In order to examine the mechanical properties of the joints, the tensile-shear tests were performed under a cross-head velocity of $1.7 \times 10^{-5} \mathrm{~m} / \mathrm{s}$ at room temperature.

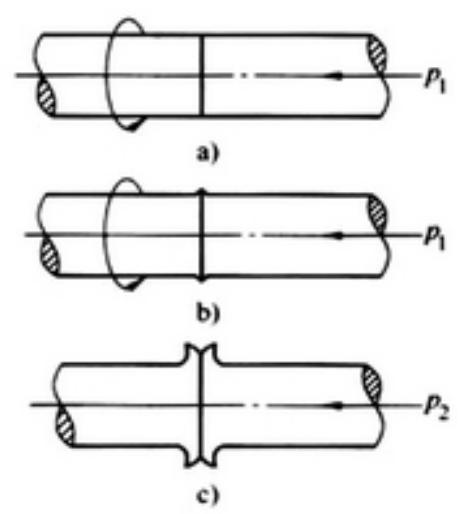

Figure 1. Schematic of friction welding process; (a) contact process; (b) welding process; (c)after welding

Table3. Summary of the welding parameters

\begin{tabular}{cccc}
\hline $\begin{array}{c}\text { Friction } \\
\text { pressure(MPa) }\end{array}$ & Friction time(s) & $\begin{array}{c}\text { Upset } \\
\text { pressure(MPa) }\end{array}$ & Upset time(s) \\
\hline 3.5 & 2.5 & 3.5 & \\
3 & 2.5 & 3.5 & 1.5 \\
2.5 & 2.5 & 3.5 & 1.5 \\
2 & 2.5 & 3.5 & 1.5 \\
2 & 2.5 & 3 & 1.5 \\
2 & 2.5 & 2.5 & 1.5 \\
2 & 2.5 & 2 & 1.5 \\
\hline
\end{tabular}

\section{results and discussion}

\section{Joint appearance}

Fig. 2 shows the appearances of $\mathrm{Mg} / \mathrm{Mg}$ joints produced at different friction force. The friction force of $\mathrm{a}$ and $\mathrm{b}$ is $2 \mathrm{kN}$ and $2.5 \mathrm{kN}$, respectively. We can observe that the flanging amount of $\mathrm{b}$ is bigger than a. The flanging amount increased with the increasing of friction froce. The flanging which caused by interface friction is a common phenomenon in the process of friction welding, meanwhile it is a necessary process. This is because the process of flanging will effectively remove the oxide from the material interface; and frictional heat creates a soft plasticized region that is no longer able to support the applied axial load and begins to deform permanently. The flanging amount should not be too big also should not be too small, this is because the joint will combined with inadequate when it is too small; and it will cause a great loss of material when it is too big. So the flanging amount should be strictly controlled in the process of friction welding. 


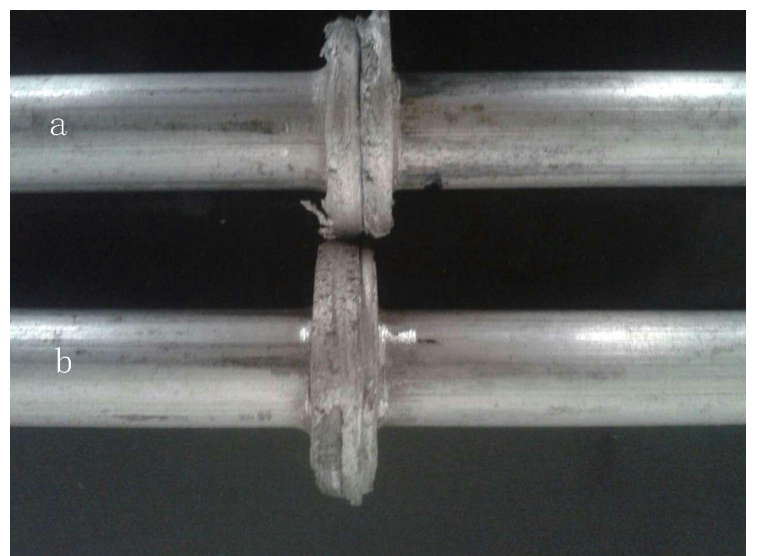

Figure 2. Weld appearance of friction welding at different friction forces

\section{Microstructure of joint}

Fig. 3 shows the microstructure of $\mathrm{Mg} / \mathrm{Mg}$ joint produced at friction force of $2 \mathrm{kN}$ and $2.5 \mathrm{kN}$. It is hard to observe the joining interface under the scan electron microscope, this suggest that the property of the joint is perfect, so $\mathrm{Mg} / \mathrm{Mg}$ joint has a certain weld-ability using friction welding.

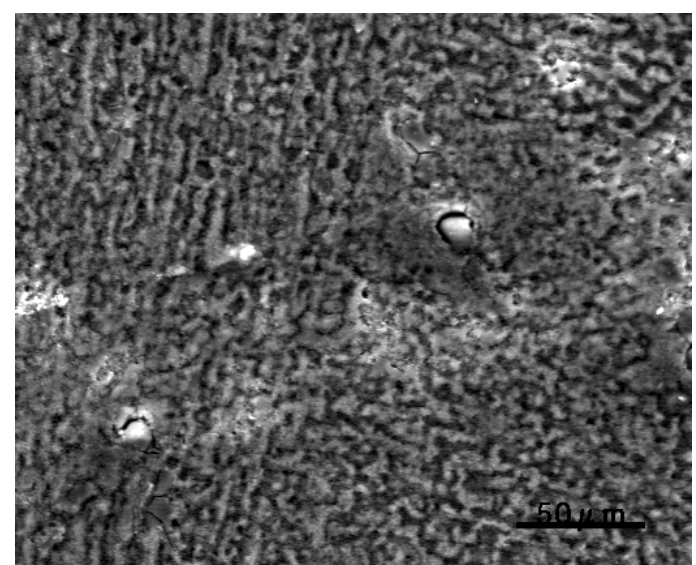

(a)

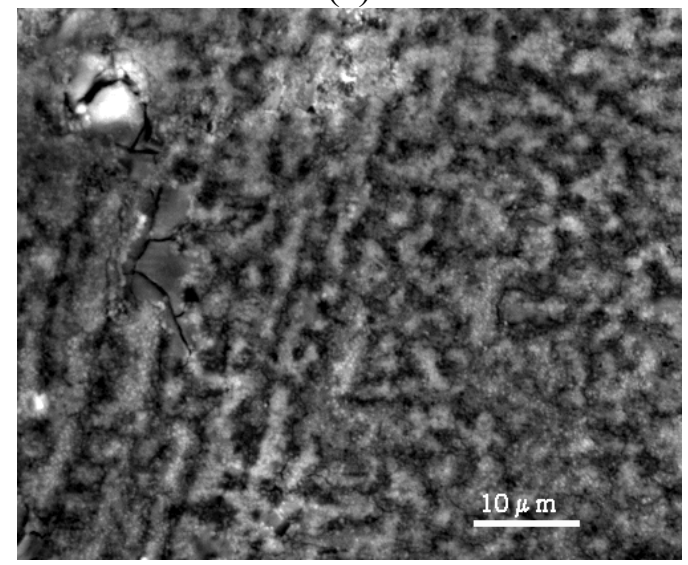

(b)

Figure 3. Microstructure of $\mathrm{Mg} / \mathrm{Mg}$ joint produced at different friction forces(a) $2 \mathrm{KN}(\mathrm{B}) 2.5 \mathrm{KN}$

\section{Mechanical properties}

Fig. 4 shows the effect of friction force on joint tensile shear load. As shown, the tensile shear load increased with the increasing of friction force. This is because the friction welding is a joining process based on the heat source obtained from the friction of the interface. In friction welding, friction force is the main factors for the heat generation. The heat generated during welding 
increased with the increase of friction force, which caused a sufficiently combination of the faying surface. So the tensile shear load is in direct proportion to the friction force.

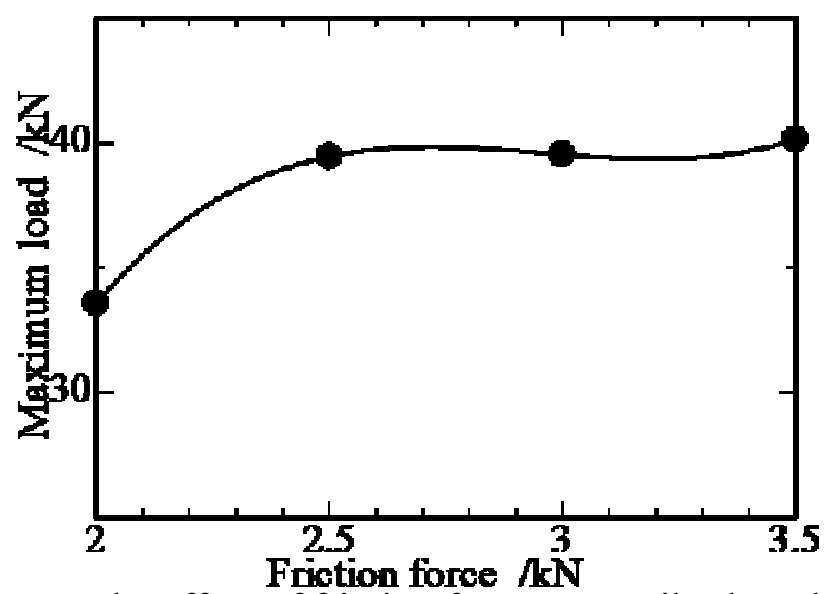

Figure 5. The effect of friction force on tensile shear load

Fig.6 shows the relationship between the tensile shear load of joint and upset force. As shown, the tensile shear load decreased with the increasing of upset force. This is attribute to the plastic metal was extruded by upset force under the welding process. So the strength of the faying surface is inverse proportion to the upset force. Meanwhile, This shows that we could obtain high quality joint when upset force is low.

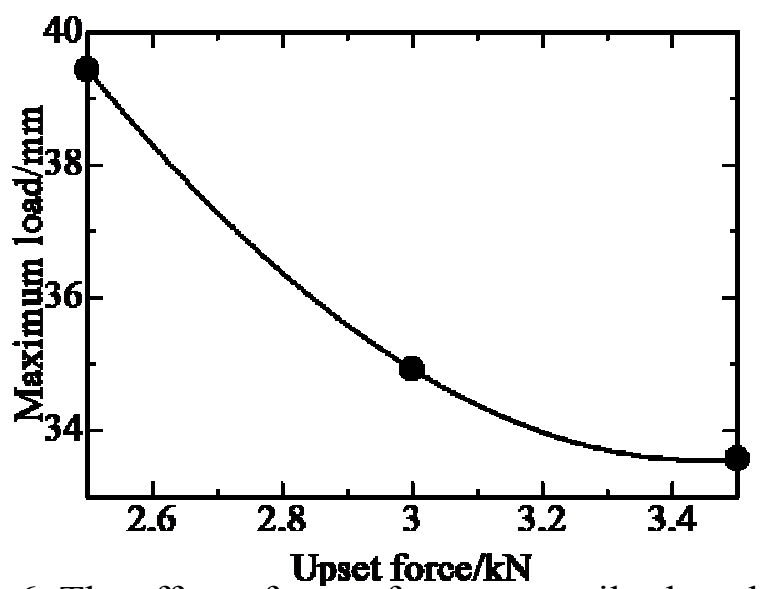

Figure 6. The effect of upset force on tensile shear load

Fig. 7 shows the effect of friction force on flanging amount and wear amount. As shown, on the one hand, the wear amount decreased with the increasing of friction force. This is because the thickness of flange increased with the increase of friction force which hindered the increase of wear amount. On the other hand, the flanging amount of rotating end and fixed end is same. This is because the stability of the magnesium performance. The flanging amount reach maximum when the friction force is $2.5 \mathrm{KN}$. 


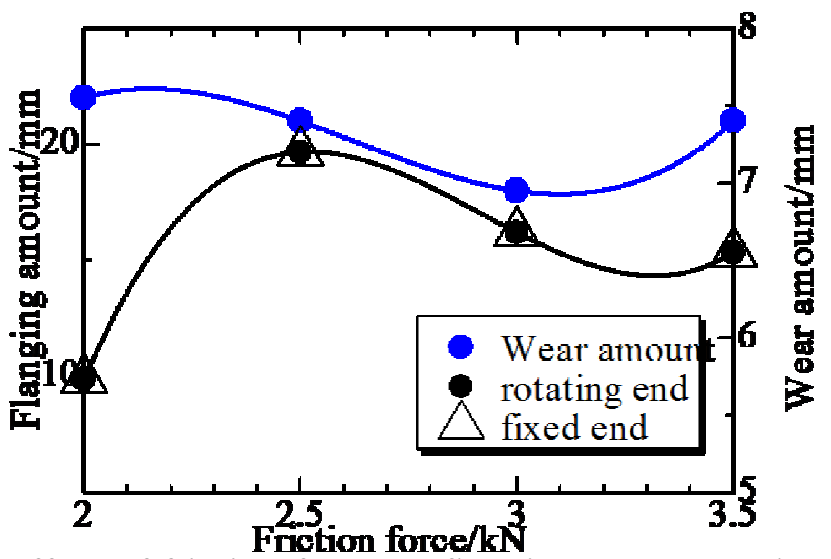

Figure 7. the effect of friction force on flanging amount and wear amount

Fig. 8 shows the effect of upset force on flanging amount and wear amount. As shown, on the one hand, the wear amount increased with the increasing of upset force. This is because the plastic metal was sufficiently extruded with the increase of upset force under welding process. On the other hand, the flanging amount of rotating end and fixed end is same. This is because the stability of the magnesium alloys performance. The flanging amount reached maximum when the upset force is $2.5 \mathrm{KN}$.

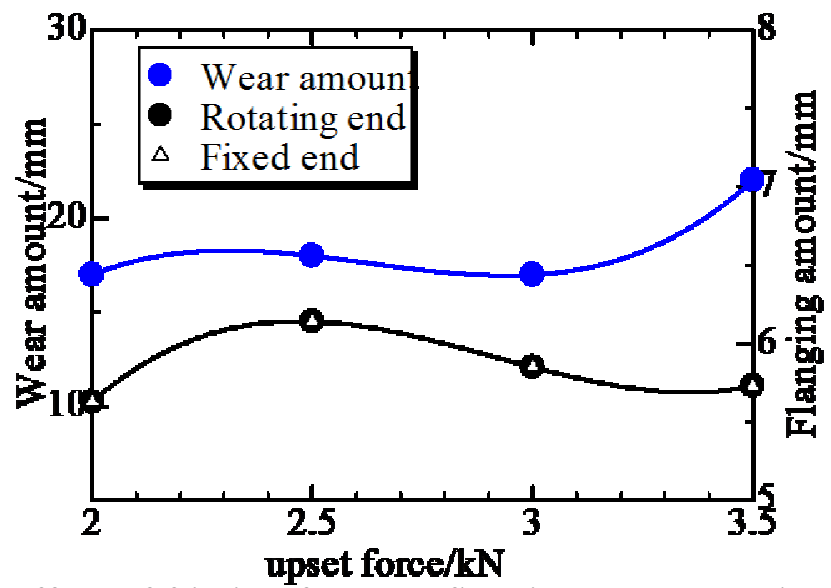

Figure 8. the effect of friction force on flanging amount and wear amount

\section{Summary}

Magnesium alloys were welded by friction welding. The mechanical properties of the joint were examined, the effects of welding parameters on the flanging amount, wear amount and tensile shear strength were investigated. The tensile shear strength increased with the increasing of friction force, whereas decreased with the increasing of upset force. The wear amount decreased with the increasing of friction force, whereas increased with the increasing of upset force.The maximum tensile shear load of $41 \mathrm{kN}$ was obtained at fricton force of $3.5 \mathrm{kN}$.

\section{Acknowledgements}

This work was supported by the Natural Science Foundation of China (grant no. U1204520), Henan Province Foundation and Advanced Technology Research Program (grant no. 122300410202), Henan Province College \& University Youth Backbone Teachers Found Project (grant no. 2013GGS-064); Natural Science Innovation Ability Cultivating Project of Henan University of Science and Technology (2014ZCX003); National Training Programs of Innovation and Entrepreneurship for Undergraduates (201310464023) and the project sponsored by SRF for ROCS, SEM. 


\section{References}

[1] Mordike BL, Ebert T. Magnesium- properties, applications, potential. J Mat Sci Eng A 2001;302:37-45

[2] Nguyen QB, Gupta M. Enhancing compressive response of AZ31B magnesium alloy using alumina nanoparticulates. Comp Sci Technol 2008;68:2185-92.

[3] ASM metals handbook, Properties and selection non-ferrous alloys and specialpurpose materials, vol. 2. $10^{\text {th }}$ ed.; 1990. p. 481.

[4] Nguyen QB, Gupta M. Microstructure and mechanical characteristics of AZ31B/A12O3 nanocomposite with addition of Ca. J Comp Mat 2009;43:5-17.

[5] Cao P, Qian Ma, John St DH. Effect of manganese on grain refinement of Mg-Al based alloys. Scripta Mater 2006;54:1853-8.

[6] Wang YN, Chang CI, Lee CJ, Lin HK, Huang JC. Texture and weak grain size dependence in friction stir processed Mg-Al-Zn alloy. Scripta Mater 2006;55:637-40. 